\title{
Chapter 7 \\ The Impact of the Expansion of Higher Education on the Rate of Return to Higher Education in Taiwan
}

\author{
Cheng-Ta Wu and Chia-Wei Tang
}

On April 10, 1994, 200 civic groups including over 30,000 people marched in the streets of Taipei, and in October of the same year, the "League for Educational Reform 4/10" was established. The protesters submitted petitions outlining four main demands: smaller schools and classes, the establishment of more high schools and universities, modernization of the education system, and the formulation of a new body of law pertaining to education. These efforts led to a dramatic increase in the number of higher education institutions, which grew in number from 60 in 1994 to 144 in $2017 .{ }^{1}$ During the same period, however, the rate of unemployment among college graduates rose from $2.52 \%$ in 1994 to $5.19 \%$ in $2017 .^{2}$

Afzal (2011) found evidence that education is the main factor determining an individual's economic status and social achievements, and further confirmed that education is the key to the development of human capital. Education can improve the productivity and efficiency of workers and can cultivate the human resources required for continued societal development and growth. The rate of return to education is defined as the economic benefits resulting from a specific educational investment. Mincer's wage equation based on the ordinary least squares (OLS) method is the most common technique used to calculate rates of return to education. The OLS method uses linear minimum mean-square error estimation to determine

\footnotetext{
${ }^{1}$ Source: Department of Statistics, Taiwan Ministry of Education, http://stats.moe.gov.tw/files/ important/OVERVIEW_U03.pdf.

${ }^{2}$ Source: Directorate General of Budget, Accounting and Statistics, Executive Yuan http://win. dgbas.gov.tw/dgbas04/bc4/manpower/year/year_t1-t24.asp?table=21\&ym=1\&yearb=82\&yeare= $106 \&$ out $=1$.

C.-T. Wu (四)

College of Education, National Chengchi University, Taipei, Taiwan, China

e-mail: chengta@nccu.edu.tw

C.-W. Tang

Center for Teacher Education, National Sun Yat-sen University, Kaohsiung, Taiwan, China

(C) The Author(s) 2020

G. Fan, T. S. Popkewitz (eds.), Handbook of Education Policy Studies,

https://doi.org/10.1007/978-981-13-8343-4_7
} 
the degree to which one additional year of education affects an individual's average wage. However, this means that OLS cannot be used to compare the rates of return to education at differing income levels. Quantile regression has also been used to estimate the rates of return to education in different quantiles pertaining to the conditional distribution of wages. This approach provides a more comprehensive picture of return-education dynamics.

Quantile regression has been applied in a variety of disciplines. In education, this method has been used to examine rates of return. Buchinsky (2001) used quantile regression to measure the rate of return to education among women in the United States. Martins and Pereira (2004) explored the relationship between education level and wage inequality, concluding that there is a positive correlation between the two. Ning (2010) examined whether the expansion of education has improved wage equality in mainland China, and argued that the effects of education are less pronounced in lower income groups. Quantile regression can be used to overcome the limitations of OLS, and may be able to shed light on the differences in the rates of return to education at various wage levels.

In this study, we used quantile regression to determine whether the expansion of higher education in Taiwan since 1994 has impacted the overall rate of return to undergraduate education. We also examined the different return rates in various fields of study such as science, engineering, and agriculture.

\subsection{Quantile Regression Model}

Quantile regression enables us to focus on the effects of explanatory variables on the conditional distribution of the dependent variable. The estimation is based on the principle of minimizing an asymmetrically weighted sum of absolute errors, which can be defined as follows:

$$
y_{i}=x_{i}^{\prime} \beta_{\theta}+\varepsilon_{i \theta} \quad i=1,2 \ldots, n
$$

where $y_{i}$ is the dependent variable selected at random from sample $Y_{i} ; x_{i}$ is the dependent variable; $\theta$ is a vector of values between 0 and $1 ; \beta_{\theta}$ is a parameter vector; and $\varepsilon_{i \theta}$ is a vector of residuals. Assuming a linear relationship, Quant $\theta_{\theta}\left(y_{i} \mid x_{i}\right)$ given $x_{i}$, the $\theta$ th conditional quantile of $y_{i}$, can be defined as

$$
\text { Quant }_{\theta}\left(y_{i} \mid x_{i}\right)=X_{i}^{\prime} \beta_{\theta}, \quad i=1,2 \ldots, n
$$

where $\beta_{\theta}$ is the vector of parameters to be estimated $(0<\theta<1)$. For a linear model, the estimator of the regression coefficient $\beta_{\theta}$ is

$$
\hat{\beta}_{\theta}=\min \left\{\sum_{i=y_{i} \geq x_{i}^{\prime} \beta} \theta\left|y_{i}-x_{i}^{\prime} \beta\right|+\sum_{i=y_{i}<x_{i}^{\prime} \beta}(1-\theta)\left|y_{i}-x_{i}^{\prime} \beta\right|\right\}
$$


In this model, various weights can be assigned to absolute values of positive and negative residuals to derive the quantile regression estimator, where $\beta_{\theta}$ indicates that the $\theta$ quantile of $y_{i}$ increases by $\beta_{\theta}$ for every unit increase in $x_{i}$. When $\theta=0.5$, we obtain the estimator of the least absolute deviation by multiplying the above estimator by 2, as follows:

$$
\widehat{\beta_{0.5}}=\sum_{i=1}^{n}\left|y_{i}-x_{i}^{\prime} \beta\right|
$$

In the case where $\theta=0.5$, quantile regression can also be referred to as median regression (i.e., a special case of quantile regression). The general form of the estimator is written as follows:

$$
\hat{\beta}_{\theta}=\min \left[\frac{1}{n} \sum_{i=1}^{n} \rho_{\theta}\left(y_{i}-x_{i}^{\prime} \beta\right)\right]=\min \left[\frac{1}{n} \sum_{i=1}^{n} \rho_{\theta}\left(\varepsilon_{i \theta}\right)\right]
$$

$\rho_{\theta}$ serves as a check function, which assigns various weights to positive and negative residuals. It is defined as follows:

$$
\begin{gathered}
\rho_{\theta}(\varepsilon)=\theta_{\varepsilon} \quad \text { if } \varepsilon \geq 0 \\
\rho_{\theta}(\varepsilon)=(\theta-1) \varepsilon \quad \text { if } \varepsilon<0
\end{gathered}
$$

Therefore, $\hat{\beta}_{\theta}$ is the $\theta$ quantile of $y_{i}$.

\subsection{Quantile Regression Results for the Rate of Return for Higher Education}

Our data sources included educational statistics from the Taiwan Ministry of Education, the Human Resources Survey Database, and the Survey Research Data Archive (SRDA). The data covered the period between 1994 and 2016. The subjects were employees ranging in age from 22 (the average age of new college graduates in Taiwan) to 65 .

Based on the human capital model proposed by Mincer (1974), ${ }^{3}$ quantile regression was used to derive the rates of return to higher education between 1994 and 2016 as well as the distribution, trends, and determinants during the period. The basic model used gender, city, marital status, education level, company size, work experience, and the square of work experience for preliminary analysis. The square of work experience served as a correction term.

\footnotetext{
${ }^{3}$ Mincer's human capital model: $\ln Y=a+b_{1} S+b_{2} E+b_{3} E^{2}+\varepsilon$
} 
Table 7.1 Quantile regression results for rate of return to higher education (1994-2016)

\begin{tabular}{l|l|l|l|l|l|l|l|l|l|l}
\hline Vector $\theta$ & 0.05 & & 0.25 & & 0.5 & & 0.75 & & 0.95 \\
\hline Year & $\beta$ & SD & $\beta$ & SD & $\beta$ & SD & $\beta$ & SD & $\beta$ & SD \\
\hline 1994 & 0.187 & 0.073 & 0.143 & 0.028 & 0.171 & 0.021 & 0.159 & 0.025 & 0.137 & 0.070 \\
\hline 1995 & 0.309 & 0.027 & 0.208 & 0.026 & 0.168 & 0.021 & 0.180 & 0.024 & 0.233 & 0.014 \\
\hline 1996 & 0.180 & 0.109 & 0.210 & 0.030 & 0.227 & 0.029 & 0.225 & 0.024 & 0.251 & 0.076 \\
\hline 1997 & 0.081 & 0.099 & 0.168 & 0.028 & 0.203 & 0.026 & 0.241 & 0.017 & 0.216 & 0.071 \\
\hline 1998 & 0.092 & 0.065 & 0.170 & 0.025 & 0.203 & 0.032 & 0.263 & 0.028 & 0.190 & 0.025 \\
\hline 1999 & 0.160 & 0.016 & 0.185 & 0.018 & 0.200 & 0.016 & 0.237 & 0.039 & 0.285 & 0.035 \\
\hline 2000 & 0.056 & 0.088 & 0.184 & 0.021 & 0.211 & 0.029 & 0.288 & 0.036 & 0.301 & 0.027 \\
\hline 2001 & 0.027 & 0.024 & 0.165 & 0.018 & 0.233 & 0.033 & 0.260 & 0.037 & 0.275 & 0.044 \\
\hline 2002 & 0.060 & 0.098 & 0.209 & 0.020 & 0.221 & 0.024 & 0.251 & 0.015 & 0.265 & 0.028 \\
\hline 2003 & 0.153 & 0.050 & 0.193 & 0.024 & 0.215 & 0.022 & 0.209 & 0.022 & 0.162 & 0.022 \\
\hline 2004 & 0.103 & 0.119 & 0.189 & 0.024 & 0.214 & 0.018 & 0.212 & 0.021 & 0.239 & 0.064 \\
\hline 2005 & 0.153 & 0.041 & 0.165 & 0.019 & 0.191 & 0.017 & 0.188 & 0.024 & 0.234 & 0.087 \\
\hline 2006 & 0.023 & 0.140 & 0.140 & 0.020 & 0.155 & 0.015 & 0.218 & 0.021 & 0.181 & 0.020 \\
\hline 2007 & 0.008 & 0.131 & 0.163 & 0.020 & 0.202 & 0.018 & 0.218 & 0.020 & 0.212 & 0.024 \\
\hline 2008 & 0.024 & 0.060 & 0.114 & 0.020 & 0.189 & 0.018 & 0.215 & 0.020 & 0.267 & 0.042 \\
\hline 2010 & 0.166 & 0.017 & 0.189 & 0.007 & 0.202 & 0.006 & 0.224 & 0.007 & 0.231 & 0.017 \\
\hline 2011 & 0.153 & 0.036 & 0.199 & 0.022 & 0.222 & 0.036 & 0.197 & 0.037 & 0.126 & 0.091 \\
\hline 2012 & -0.030 & 0.195 & 0.093 & 0.038 & 0.110 & 0.031 & 0.136 & 0.019 & 0.166 & 0.060 \\
\hline 2013 & 0.053 & 0.053 & 0.105 & 0.017 & 0.129 & 0.017 & 0.139 & 0.019 & 0.235 & 0.032 \\
\hline 2014 & 0.153 & 0.103 & 0.100 & 0.037 & 0.108 & 0.043 & 0.158 & 0.040 & 0.139 & 0.023 \\
\hline 2015 & -0.240 & 0.438 & 0.036 & 0.040 & 0.144 & 0.049 & 0.219 & 0.055 & 0.216 & 0.115 \\
\hline 2016 & -0.655 & 0.172 & 0.003 & 0.034 & 0.099 & 0.029 & 0.149 & 0.028 & 0.118 & 0.082 \\
\hline
\end{tabular}

Note: $\beta$ refers to quantile regression coefficients, SD refers to standard deviation

Table 7.1 presents a summary of the quantile regression results for the rate of return for higher education from 1994 to 2016. The quantile regression coefficients were estimated at five $\theta$ levels: the 5th, 25th, 50th, 75th, and 95th quantiles.

The results in Table 7.1 can be used to visualize the distribution of the rate of return to higher education (Fig. 7.1), where the $\mathrm{X}$-axis indicates the year and the Y-axis indicates the coefficient of the rate of return to higher education. Based on the estimates for the 0.5 quantile, the rate of return to higher education indicated a gradual decline during this timeframe.

Table 7.2 summarizes the quantile regression results for 2016. Taking education level as an example, the positive coefficient indicates that employees with an undergraduate degree received higher wages than those without one. There were also significant relationships between work experience/wages and gender/wages, suggesting that male employees and those with more work experience earn more. The coefficient for marital status is negative but not significant, which indicates that there is no significant difference in wages between married and unmarried individuals. The coefficient of the square of work experience was negative, suggesting a 


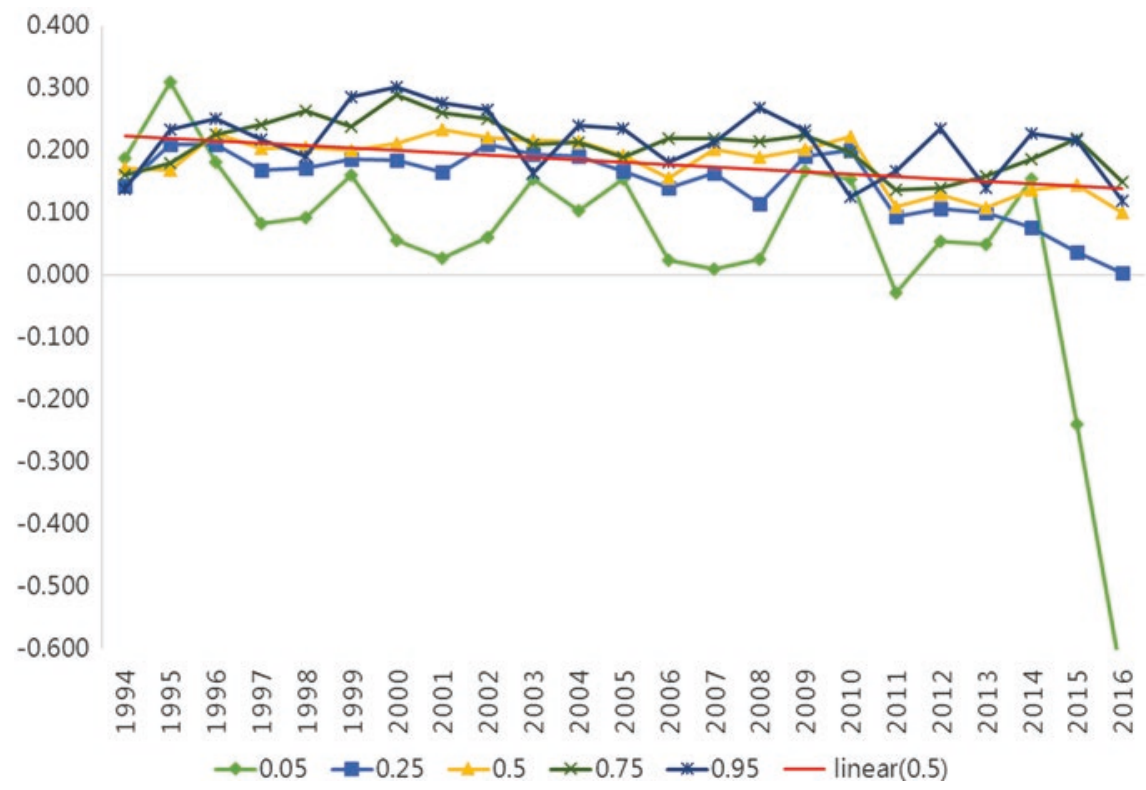

Fig. 7.1 The rate of return to higher education from 1994 to 2016

negative correlation with wages. This is consistent with the assumption of Mincer's human capital model that age and wages present an inverted U-shaped correlation.

\subsection{Quantile Regression Results for the Rates of Return to Higher Education in Various Fields of Study}

Based on the SRDA ${ }^{4}$ database, various fields of study were divided into the following ten categories: humanities, law, business, science, engineering, agriculture, health care, military/law enforcement, education, and others. In this study, we used agriculture (with the lowest average wage in 2016) as a reference point by which to compare the rates of return to higher education in different fields of study.

Table 7.3 and Fig. 7.2 list the estimated rates of return to higher education in the 0.5 quantile from 1994 to 2016 . These results show that-over the 20-year period of educational reform-employees who obtained education enjoyed the highest average rate of return at $23.8 \%$. Looking back at 1994 , health care, education, and humanities had the highest rates of return; whereas engineering, business, and military/law enforcement had the lowest return rates. Over the last 5 years, all fields have seen significant decreases in their rate of return to higher education (except for

${ }^{4}$ SRDA, Survey Research Data Archive. https://srda.sinica.edu.tw/. 
Table 7.2 Rate of return to investment in higher education in 2016 (partial)

\begin{tabular}{|c|c|c|c|c|c|}
\hline & Quantile & Coefficient & SD & $T$ value & Significance \\
\hline \multirow[t]{5}{*}{ Constant } & 0.05 & 9.5260 & 0.0225 & 424.3870 & $* * *$ \\
\hline & 0.25 & 9.8644 & 0.0062 & 1586.2826 & $* * *$ \\
\hline & 0.50 & 9.9742 & 0.0067 & 1498.8952 & $* * *$ \\
\hline & 0.75 & 10.0760 & 0.0079 & 1277.9861 & $* * *$ \\
\hline & 0.95 & 10.3403 & 0.0224 & 461.3845 & $* * *$ \\
\hline \multirow[t]{5}{*}{ Gender } & 0.05 & 0.1128 & 0.0135 & 8.3315 & $* * *$ \\
\hline & 0.25 & 0.1501 & 0.0050 & 30.0284 & $* * *$ \\
\hline & 0.50 & 0.1787 & 0.0052 & 34.0827 & $* * *$ \\
\hline & 0.75 & 0.2179 & 0.0062 & 35.3842 & $* * *$ \\
\hline & 0.95 & 0.2315 & 0.0169 & 13.7277 & $* * *$ \\
\hline \multirow[t]{5}{*}{ Marital status } & 0.05 & 0.0336 & 0.0124 & 2.7136 & $* *$ \\
\hline & 0.25 & 0.0597 & 0.0049 & 12.1474 & $* * *$ \\
\hline & 0.50 & 0.0827 & 0.0052 & 16.0393 & $* * *$ \\
\hline & 0.75 & 0.1204 & 0.0063 & 19.0684 & $* * *$ \\
\hline & 0.95 & 0.2279 & 0.0161 & 14.1184 & $* * *$ \\
\hline \multirow[t]{5}{*}{ Education } & 0.05 & -0.6551 & 0.1723 & -3.8016 & $* * *$ \\
\hline & 0.25 & 0.0028 & 0.0338 & 0.0840 & \\
\hline & 0.50 & 0.0995 & 0.0287 & 3.4690 & $* * *$ \\
\hline & 0.75 & 0.1491 & 0.0284 & 5.2523 & $* * *$ \\
\hline & 0.95 & 0.1183 & 0.0821 & 1.4408 & \\
\hline \multirow[t]{5}{*}{ Work experience } & 0.05 & 0.0351 & 0.0030 & 11.8659 & $* * *$ \\
\hline & 0.25 & 0.0249 & 0.0010 & 25.1862 & $* * *$ \\
\hline & 0.50 & 0.0265 & 0.0010 & 25.9320 & $* * *$ \\
\hline & 0.75 & 0.0294 & 0.0011 & 26.0869 & $* * *$ \\
\hline & 0.95 & 0.0335 & 0.0030 & 11.3414 & $* * *$ \\
\hline \multirow[t]{5}{*}{ Square of work experience } & 0.05 & -0.0009 & 0.0001 & -8.4458 & $* * *$ \\
\hline & 0.25 & -0.0005 & 0.0000 & -12.6077 & $* * *$ \\
\hline & 0.50 & -0.0004 & 0.0000 & -10.2838 & $* * *$ \\
\hline & 0.75 & -0.0004 & 0.0000 & -9.9491 & $* * *$ \\
\hline & 0.95 & -0.0005 & 0.0001 & -4.6398 & $* * *$ \\
\hline
\end{tabular}

Note: $* p<0.05, * * p<0.01, * * * p<0.001$

military/law enforcement where the decline has been far less pronounced). For 2016, law, military/law enforcement, and education enjoyed the highest rates of return, whereas business and engineering saw the lowest rates.

Overall, the rates of return to higher education in most fields of study were unstable or declined during the period from 1994 to 2016. However, the return rates for military/law enforcement grew steadily, whereas the rates for health care remained largely unchanged.

Tables 7.4 and 7.5 compare the quantile regression coefficients in various fields of study using estimates for five quantiles for the years from 1994 to 2016.

In 1994, among lower-income workers, those in the fields of education, humanities, law, and health care enjoyed higher rates of return to higher education. Among higher-income workers, those in the fields of law, science, and health care enjoyed 
higher return rates. In the field of health care, we observed a significant difference between higher- and lower-income workers in terms of the rates of return to higher education.

In 2016, among lower-income workers, those in the fields of education, military/ law enforcement, and health care enjoyed higher rates of return to higher education. Among higher-income workers, those in the fields of law, military/law enforcement, and health care enjoyed higher return rates.

Table 7.6 summarizes the regression results for the 0.5 quantile in the various fields of study in 2016. Overall, these results indicate a positive correlation between education level and income. Work experience, region, gender, and marital status also demonstrated significant relationships with income. Specifically, employees earning higher wages were those with more work experience, those located in six specific municipalities (the largest cities in Taiwan), males, and married individuals. The square of job experience was negatively correlated with wages, which is in line with the assumption of Mincer's human capital model.

In summary, our results indicate that education, work experience, location in urban areas, being male, and marital status are all significantly correlated with income level, whereas the square of work experience is negatively correlated with income level. During the last 20 years of educational reform, the overall rate of return to higher education has gradually declined, regardless of the field of study. On average, the fields of law, humanities, and military/law enforcement enjoyed higher relative return rates. It is also worth noting that the field of health care had high rates of return among higher-income workers. Military/law enforcement was the only field that demonstrated steady increases during this period, perhaps due to the government's decision to provide financial support for students enrolled in police academies beginning in 1993.

\subsection{Conclusions}

This study used quantile regression to analyze the rates of return to higher education in Taiwan during the period of educational reform between 1994 and 2016. We focused on the variations in the rates of return to education in different wage quantiles and their distribution over the last 20 years. The results indicate a declining trend in the overall rate of return to education, particularly in the 0.05 quantile. This may be due to the expansion of higher education since 1997, which has resulted in there being 126 institutions of higher education in Taiwan and more than 300,000 graduates in 2016. The expansion of higher education has limited the importance of university diplomas in the search for employment. The consequences of overeducation should be explored further and managed carefully.

In this study, we used agriculture (the sector with the lowest average wage) as a reference point by which to compare the rates of return among various fields of study. The results indicate that the field of education has enjoyed the highest rate of return over the last 20 years. The rates of return in all fields, except for military/law 
Table 7.3 Rates of return to higher education in the 0.5 quantile for various fields of study

\begin{tabular}{l|l|l|l|l|l|l|l|l}
\hline Year & Humanities & Law & Business & Science & Engineering & $\begin{array}{l}\text { Health } \\
\text { care }\end{array}$ & $\begin{array}{l}\text { Military/law } \\
\text { enforcement }\end{array}$ & Education \\
\hline 1994 & 0.1490 & 0.1360 & 0.0366 & 0.0846 & -0.0055 & 0.1603 & 0.0378 & 0.1547 \\
\hline 1995 & 0.1627 & 0.1659 & 0.0627 & 0.1099 & -0.0042 & 0.2219 & 0.0713 & 0.1671 \\
\hline 1996 & 0.1122 & 0.0767 & 0.0272 & 0.0917 & -0.0645 & 0.1513 & -0.0040 & 0.1610 \\
\hline 1997 & 0.1573 & 0.1204 & 0.0361 & 0.1049 & -0.0526 & 0.1830 & 0.0267 & 0.2004 \\
\hline 1998 & 0.1393 & 0.1273 & 0.0217 & 0.1279 & -0.0162 & 0.1796 & 0.0664 & 0.2117 \\
\hline 1999 & 0.1585 & 0.1870 & 0.0234 & 0.1696 & -0.0325 & 0.1958 & 0.0847 & 0.2199 \\
\hline 2000 & 0.1504 & 0.1316 & 0.0239 & 0.1422 & -0.0445 & 0.1846 & 0.0945 & 0.1851 \\
\hline 2001 & 0.1743 & 0.1868 & -0.0010 & 0.1346 & -0.0537 & 0.1910 & 0.1066 & 0.2151 \\
\hline 2002 & 0.1517 & 0.2354 & 0.0191 & 0.1360 & -0.0294 & 0.1800 & 0.1405 & 0.2437 \\
\hline 2003 & 0.1393 & 0.2079 & 0.0325 & 0.0807 & -0.0140 & 0.2075 & 0.1727 & 0.2659 \\
\hline 2004 & 0.1566 & 0.2110 & 0.0278 & 0.1183 & -0.0053 & 0.2126 & 0.1547 & 0.2509 \\
\hline 2005 & 0.1201 & 0.2252 & 0.0264 & 0.1515 & -0.0156 & 0.1925 & 0.2165 & 0.2491 \\
\hline 2007 & 0.1587 & 0.2526 & 0.0498 & 0.1065 & 0.0127 & 0.2177 & 0.2462 & 0.2511 \\
\hline 2008 & 0.1524 & 0.1780 & 0.0184 & 0.0595 & -0.0063 & 0.1951 & 0.2195 & 0.2794 \\
\hline 2009 & 0.1220 & 0.2316 & 0.0041 & 0.0596 & 0.0111 & 0.1799 & 0.2457 & 0.2542 \\
\hline 2010 & 0.0706 & 0.2565 & -0.0145 & 0.0594 & -0.0361 & 0.1355 & 0.2066 & 0.2078 \\
\hline 2011 & 0.2138 & 0.3644 & 0.0946 & 0.1660 & 0.0887 & 0.2713 & 0.3167 & 0.3435 \\
\hline 2012 & 0.1552 & 0.3372 & 0.0680 & 0.1525 & 0.0598 & 0.2639 & 0.3230 & 0.3437 \\
\hline 2013 & 0.1185 & 0.2949 & 0.0853 & 0.1628 & 0.0739 & 0.2771 & 0.3207 & 0.2987 \\
\hline 2014 & 0.0995 & 0.3771 & 0.0634 & 0.0883 & 0.0398 & 0.3133 & 0.2863 & 0.2700 \\
\hline 2015 & 0.0786 & 0.2831 & 0.0303 & 0.0948 & 0.0084 & 0.2350 & 0.3248 & 0.2090 \\
\hline 2016 & 0.1158 & 0.3489 & 0.0552 & 0.0922 & 0.0560 & 0.2154 & 0.3405 & 0.2745 \\
\hline Mean & 0.138 & 0.224 & 0.035 & 0.111 & -0.002 & 0.236 & 0.183 & 0.238 \\
\hline Rank & 5 & 3 & 7 & 5 & 8 & 2 & 4 & 1 \\
\hline & & & & & & & &
\end{tabular}

enforcement, have been declining gradually. This is a clear indication that educational reform should consider the divergent needs of the labor market and reconsider whether the continued expansion of higher education is the best approach to improve human resources.

Finally, we would like to provide suggestions for future work in this area. We recommend that future studies consider using more up-to-date data (this study used data from 1994 to 2016), especially the salary adjustment statistics, which might contribute to a more accurate estimation of the relationship among employees' demographics, work environments, and the rates of return to education in different fields of study as well as the effects of education on the development of human resources. Furthermore, this study was based on secondary data that was limited by the fixed structure of the official database. If we can integrate information collected at different stages of schooling, we can gain a more comprehensive understanding of how each educational stage affects the development of students, which-in turn-will enable us to better understand the contribution of higher education to human capital. 


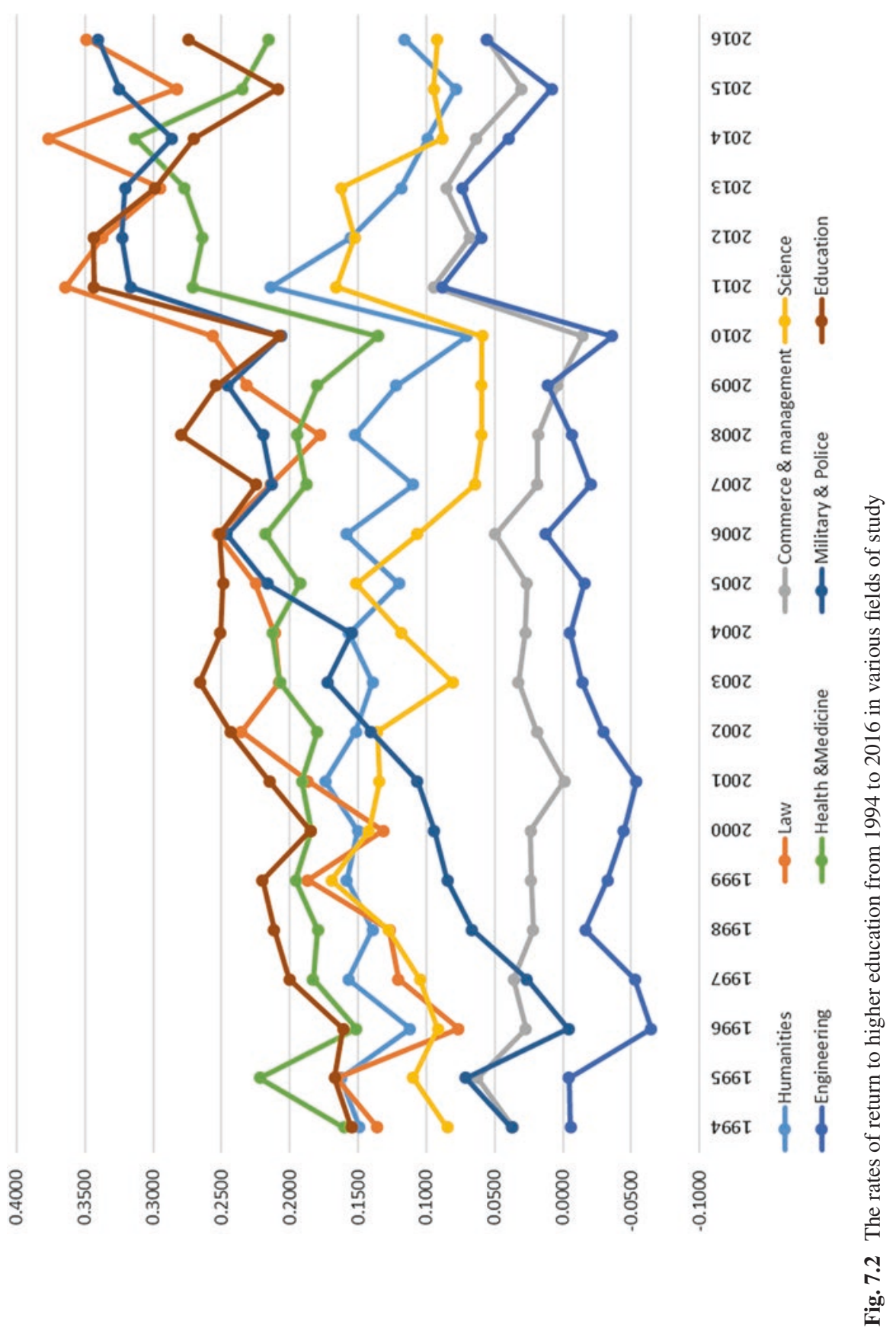


Table 7.4 Quantile regression coefficients in various fields of study for five quantiles in 1994

\begin{tabular}{|c|c|c|c|c|c|c|c|c|}
\hline $\begin{array}{l}\text { PR } \\
(0.05- \\
0.95)\end{array}$ & Humanities & Law & Business & Science & Engineering & $\begin{array}{l}\text { Health } \\
\text { care }\end{array}$ & $\begin{array}{l}\text { Military/law } \\
\text { enforcement }\end{array}$ & Education \\
\hline 0.05 & 0.1238 & 0.1094 & 0.0458 & 0.0480 & 0.0419 & 0.1082 & -0.0946 & 0.1352 \\
\hline 0.25 & 0.1624 & 0.1409 & 0.0770 & 0.0666 & 0.0363 & 0.1786 & 0.0320 & 0.1755 \\
\hline 0.50 & 0.1490 & 0.1360 & 0.0366 & 0.0846 & -0.0055 & 0.1603 & 0.0378 & 0.1547 \\
\hline 0.75 & 0.1402 & 0.1571 & 0.0472 & 0.1380 & -0.0213 & 0.1865 & -0.0027 & 0.1451 \\
\hline 0.95 & 0.0992 & 0.4014 & 0.1118 & 0.0958 & 0.0245 & 0.4749 & 0.0226 & 0.1138 \\
\hline
\end{tabular}

Table 7.5 Quantile regression coefficients in various fields of study for five quantiles in 2016

\begin{tabular}{l|l|l|l|l|l|l|l|l}
\hline $\begin{array}{l}\text { PR } \\
(0.05- \\
0.95)\end{array}$ & Humanities & Law & Business & Science & Engineering & $\begin{array}{l}\text { Health } \\
\text { care }\end{array}$ & $\begin{array}{l}\text { Military/law } \\
\text { enforcement }\end{array}$ & Education \\
\hline 0.05 & 0.8300 & 0.7669 & 0.8435 & 0.7747 & 0.8318 & 0.8867 & 0.8794 & 0.9064 \\
\hline 0.25 & 0.1633 & 0.3277 & 0.1388 & 0.1288 & 0.1401 & 0.2408 & 0.4250 & 0.3028 \\
\hline 0.50 & 0.1158 & 0.3489 & 0.0552 & 0.0922 & 0.0560 & 0.2154 & 0.3405 & 0.2745 \\
\hline 0.75 & 0.1298 & 0.4062 & 0.0464 & 0.1074 & 0.0284 & 0.2696 & 0.3032 & 0.2439 \\
\hline 0.95 & 0.1996 & 0.4719 & 0.1476 & 0.1138 & 0.0824 & 0.6853 & 0.2404 & 0.2144 \\
\hline
\end{tabular}

Table 7.6 Regression results of rates of return to education in various fields of study in 2016

\begin{tabular}{l|l|l|l|l|l}
\hline & Coefficient & SD & $T$ value & $P$-value & Significance \\
\hline Constant & 9.9742 & 0.0067 & 1498.8952 & 0.0000 & $* * *$ \\
\hline Humanities & 0.1158 & 0.0335 & 3.4616 & 0.0005 & $* * *$ \\
\hline Law & 0.3489 & 0.0704 & 4.9585 & 0.0000 & $* * *$ \\
\hline Business & 0.0552 & 0.0289 & 1.9119 & 0.0559 & \\
\hline Engince & 0.0922 & 0.0368 & 2.5070 & 0.0122 & $*$ \\
\hline Health care & 0.0560 & 0.0290 & 1.9319 & 0.0534 & \\
\hline Military/law enforcement & 0.2154 & 0.0317 & 6.7888 & 0.0000 & $* * *$ \\
\hline Education & 0.3405 & 0.0338 & 10.0885 & 0.0000 & $* * *$ \\
\hline Located in six municipalities & 0.2745 & 0.0334 & 8.2078 & 0.0000 & $* * *$ \\
\hline Male & 0.0378 & 0.0048 & 7.8489 & 0.0000 & $* * *$ \\
\hline Married & 0.1787 & 0.0052 & 34.0827 & 0.0000 & $* * *$ \\
\hline Smaller companies & 0.0827 & 0.0052 & 16.0393 & 0.0000 & $* * *$ \\
\hline Medium-sized companies & 0.0283 & 0.0096 & 2.9448 & 0.0032 & $* * *$ \\
\hline Larger companies & 0.0350 & 0.0111 & 3.1552 & 0.0016 & $* *$ \\
\hline Undergraduate degree & 0.0769 & 0.0070 & 10.9949 & 0.0000 & $* * *$ \\
\hline Postgraduate & 0.0995 & 0.0287 & 3.4690 & 0.0005 & $* * *$ \\
\hline Years of work experience & 0.4111 & 0.0301 & 13.6504 & 0.0000 & $* * *$ \\
\hline Square of work experience & 0.0265 & 0.0010 & 25.9320 & 0.0000 & $* * *$ \\
\hline
\end{tabular}

Note: $* p<0.05, * * p<0.01, * * * p<0.001$ 


\section{References}

Afzal, M. (2011). Microeconometric analysis of private returns to education and determinants of earnings. Pakistan Economic and Social Review, 49(1), 39-68.

Buchinsky, M. (2001). Quantile regression with sample selection: Estimating women's return to education in the US. Empirical Economics, 26(1), 87-113.

Martins, P. S., \& Pereira, P. T. (2004). Does education reduce wage inequality? Quantile regression evidence from 16 European countries. Labour Economics, 11, 355-371.

Mincer, J. (1974). Schooling, experience and earnings. New York: National Bureau of Economic Research.

Ning, G. (2010). Can Educational Expansion Improve Income Inequality? Evidences from the CHNS 1997 and 2006 data. Economic Systems, 34(4), 397-412.

Cheng-Ta Wu is President of University of Kang Ning (Taipei), Professor of Graduate Institute of Educational Policy and Administration at National Chengchi University (Taipei), Director of the Education Administration Associate and the Cross-Strait Cultural and Educational Research Associate, Convener of the Editorial Board for the Journal of Education \& Psychology (TSSCI Journal), Editor-in-Chief of the Journal of Education Research. His main research is in educational policy analysis, educational administration, and educational statistics. E-mail: chengta@nccu.edu. tw, profwuchengta@gmail.com.

Chia-Wei Tang is Associate Professor in Education within the Center for Teacher Education at Sun Yat-sen University (Taiwan). His main research is in educational policy analysis and educational administration.

Open Access This chapter is licensed under the terms of the Creative Commons Attribution 4.0 International License (http://creativecommons.org/licenses/by/4.0/), which permits use, sharing, adaptation, distribution and reproduction in any medium or format, as long as you give appropriate credit to the original author(s) and the source, provide a link to the Creative Commons licence and indicate if changes were made.

The images or other third party material in this chapter are included in the chapter's Creative Commons licence, unless indicated otherwise in a credit line to the material. If material is not included in the chapter's Creative Commons licence and your intended use is not permitted by statutory regulation or exceeds the permitted use, you will need to obtain permission directly from the copyright holder.

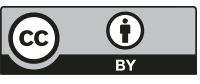

